\title{
GERMINAÇÃO DE SEMENTES E EMERGÊNCIA DE PLÂNTULAS DE Tabebuia rosea (Bertoloni) A.P. DE CANDOLLE (BIGNONIACEAE), UMA ESPÉCIE EXÓTICA COM POTENCIAL INVASOR ${ }^{1}$
}

\author{
Fábio Socolowski² e Massanori Takaki²
}

\begin{abstract}
RESUMO - Este estudo teve por objetivo determinar os efeitos da temperatura e da luz na germinação de sementes de Tabebuia rosea, bem como avaliar a influência dos ambientes de pleno sol e sob dossel na emergência de suas plântulas. Foram testadas temperaturas constantes de 10 a $45^{\circ} \mathrm{C}$ com intervalos de $5^{\circ} \mathrm{C}$, sob luz branca e escuro. Verificou-se que a faixa ótima de temperatura para a germinação foi de 20 a $40^{\circ} \mathrm{C}$ na luz e de 20 a $35^{\circ} \mathrm{C}$ no escuro. As sementes apresentaram maior sincronização da germinação a $25^{\circ} \mathrm{C}$ na luz e $30^{\circ} \mathrm{C}$ no escuro. Os resultados indicam que as sementes de Tabebuia rosea podem germinar em ampla faixa de temperatura, tanto em ambientes abertos, com disponibilidade de luz, quanto em locais com ausência de luz, enterradas no solo ou, mesmo, no interior das florestas. Essa germinação, bem como o recrutamento das plântulas, tanto a pleno sol quanto sob a sombra da vegetação, indica o potencial invasor da espécie.
\end{abstract}

Palavras-chave - Tabebuia rosea, germinação, luz e temperaturas cardeais.

\section{SEED GERMINATION AND SEEDLING EMERGENCE OF Tabebuia rosea (Bertoloni) A.P. DE CANDOLLE (BIGNONIACEAE), AN EXOTIC SPECIES WHITH INVASIVE POTENTIAL}

\begin{abstract}
The objective of the present work was to analyze temperature and light effects on seed germination of Tabebuia rosea, as well as to evaluate the influence of sun and shade environments on seedlings emergence and recruitment. Constant temperatures from 10 to $45^{\circ} \mathrm{C}$, with $5^{\circ} \mathrm{C}$ intervals, under white light and dark regimes were tested. The optimum temperature range for seed germination was between 20 and $40^{\circ} \mathrm{C}$ under white light and 20 to $35^{\circ} \mathrm{C}$ under dark. High synchronization index of seed germination was obtained at $25^{\circ} \mathrm{C}$ under white light and $30^{\circ} \mathrm{C}$ in dark. Our results indicate that seeds of Tabebuia rosea can germinate in a wide range of temperature in open environments and in places where light do not reach, buried in the soil or beneath the forest canopy. The seed germination and recruitment percentage under both direct sun light and canopy indicate the invasion potential of the species.
\end{abstract}

Keywords: Tabebuia rosea, germination, light, and cardinal temperatures.

\section{INTRODUÇÃO}

A temperatura e a luz são os principais fatores ambientais que promovem a germinação de sementes em solos com boa disponibilidade hídrica (ANDRADE, 1995). A temperatura pode influenciar o estado de dormência e, ao mesmo tempo, modular a germinação de sementes não dormentes (BENECH-ARNOLD e SÁNCHEZ, 1995). De acordo com Baskin e Baskin (1998), além da temperatura, existem outros fatores ambientais que podem causar alterações no estado de dormência, como a presença ou ausência de luz e altas temperaturas,

\footnotetext{
${ }^{1}$ Recebido em 24.08.2006 e aceito para publicação em 08.12.2006.

${ }^{2}$ Departamento de Botânica - UNESP - Cx.P. 199, 13506-900 Rio Claro, SP.
} 
induzindo a dormência em sementes quiescentes ou promovendo a germinação daquelas dormentes.

Devido ao alto índice de área foliar observado em florestas tropicais, a luz é o fator determinante na vida das plantas no interior da floresta (LÜTTGE, 1997). A radiação solar ao atravessar o dossel de uma floresta sofre mudanças devido à absorção seletiva do espectro da radiação pelas folhas (FEDERER e TANNER, 1966), resultando em uma baixa razão vermelho:vermelho extremo na luz filtrada (FENNER, 1995). Tais ambientes não são propícios para a germinação de sementes de espécies pioneiras fotossensíveis, que têm sua germinação drasticamente reduzida em baixa razão vermelho:vermelho extremo (VÁLIO e SCARPA, 2001).

A germinação controlada pela temperatura e pela luz é importante para o recrutamento e estabelecimento de plântulas em clareiras de florestas, que consistem em ambientes com grande aporte de energia radiante (VAZQUEZ-YANES et al., 1990). Essa disponibilidade de radiação solar influencia a variação da temperatura e umidade do ar e da temperatura do solo (PEZZOPANE et al., 2002). Assim, clareiras grandes podem apresentar muitos sítios de regeneração tanto para espécies tolerantes à sombra, em sua periferia, quanto para espécies que necessitam de luz para germinar, em sua área central (BROWN, 1996).

Tabebuia rosea (Bertoloni) A.P. de Candolle é uma espécie arbórea, da família Bignoniaceae, que atinge altura de 25 a $30 \mathrm{~m}$, possui folhas palmadas com cinco folíolos, inflorescências terminais com flores rosadas a margenta com interior amarelo. Seus frutos são cápsulas linear-cilíndricas, atenuadas nas extremidades, contendo sementes anemocóricas. Ocorre naturalmente desde o sudeste do México até a Venezuela e costa do Equador em várias formações florestais, mas especialmente em florestas paludosas, além de ser amplamente cultivada desde o nível do mar até altitudes de $1.200 \mathrm{~m}$, apresentando como sinonímias Tecoma rosea Bertoloni, Tecoma mexicana Martius ex A.P. de Candolle, Tabebuia pentaphylla (Linnaeus) Hemsley, Couralia rosea (Bertoloni) Donnell Smith, Tecoma punctatissima Kränzlin e Tabebuia punctatissima (Kränzlin) Standley (GENTRY, 1992). Na Venezuela, é uma das espécies amplamente utilizadas na carpintaria; em outros paises, como no Canadá e Estados Unidos, é empregada como planta ornamental (VIT, 2004). No Brasil, é amplamente utilizada na arborização de parques, ruas e avenidas devido ao seu florescimento intenso, rusticidade e rápido crescimento (LORENZI et al., 2003).

Muitas das espécies vegetais exóticas utilizadas na ornamentação vêm-se tornando invasoras nos locais em que foram introduzidas (WEBSTER et al., 2005), adaptando-se com maior facilidade a ambientes similares aos encontrados em sua região de origem (ZILLER, 2001). É possível predizer o sucesso de uma espécie com base em informações de como a germinação se distribuí ao longo do tempo, permitindo o recrutamento no ambiente de parte de suas plântulas (RANAL e SANTANA, 2006).

Este estudo teve como objetivo contribuir com informações ecofisiológicas dos efeitos da luz e da temperatura na germinação de sementes de Tabebuia rosea, bem como da influência dos ambientes de sol e sombra na emergência e recrutamento de suas plântulas.

\section{MATERIAL E MÉTODOS}

As sementes de Tabebuia rosea foram colhidas, em novembro de 2003, de 11 indivíduos com cerca de 20 anos de idade, localizados no Campus da Universidade Estadual Paulista (UNESP), em Rio Claro, $\mathrm{SP}$, provenientes de diferentes produtores de mudas de várias regiões do Estado de São Paulo. As sementes colhidas foram deixadas para secar por dois dias em sala aclimatizada em $25^{\circ} \mathrm{C}$ e armazenadas em recipientes fechados de vidro a $10^{\circ} \mathrm{C}$ até o início dos experimentos. Os experimentos de temperatura e luz tiveram início após cinco meses de armazenamento das sementes e foram realizados em germinadores (modelo 347-G da FANEM e modelo MA 403, da MARCONI) no Laboratório de Fotomorfogênese de Plantas do Departamento de Botânica da UNESP, Rio Claro. Em todos os experimentos foram utilizadas quatro repetições de 25 sementes cada.

As sementes foram semeadas em caixas plásticas do tipo "gerbox" forradas com papel-filtro e umedecidas, inicialmente, com $10 \mathrm{~mL}$ de água destilada; quando necessário, mais água foi adicionada ao longo do experimento. $\mathrm{O}$ monitoramento dos experimentos foi realizado diariamente, com a contagem e retirada das sementes consideradas germinadas, as quais apresentaram comprimento mínimo da radícula de $1 \mathrm{~mm}$. Nos experimentos conduzidos no escuro, as sementes foram observadas sob luz verde de segurança (AMARALBAROLI e TAKAKI, 2001). Foram testadas temperaturas 
constantes de 10 a $45^{\circ} \mathrm{C}$, com intervalos de $5^{\circ} \mathrm{C}$, em condições de luz branca fluorescente constante ( 2 lâmpadas fluorescentes do tipo luz do dia de $15 \mathrm{~W}$ cada, com fluência de $32,85 \mu \mathrm{mol} . \mathrm{m}^{-2} . \mathrm{s}^{-1}$ ao nível da semente) e escuro. Os experimentos foram encerrados quando as porcentagens de germinação se mantiveram constantes por cinco dias consecutivos. Como a germinação não ocorreu nas temperaturas extremas de 10 e $45^{\circ} \mathrm{C}$, estes dados foram excluídos das análises estatísticas.

Os experimentos para avaliação dos efeitos dos ambientes de sol e sombra natural na emergência das plântulas tiveram início em junho de 2004 e foram realizados no Jardim Experimental do Departamento de Botânica da UNESP de Rio Claro. Dois ambientes com características de luminosidade distintas foram determinados, um a pleno sol e outro na sombra, localizados sob a copa das árvores em um bosque, com as características espectrais distintas (Figura 1). Foram utilizadas 16 réplicas de 25 sementes de $T$. rosea, semeadas a uma profundidade de um centímetro em sacos pretos $(20 \times 40 \mathrm{~cm})$, contendo uma mistura de $50 \%$ de solo e $50 \%$ de húmus de minhoca. Diariamente, os experimentos foram regados com água, sendo considerado como emergência a abertura dos cotilédones. A emergência foi avaliada diariamente, juntamente com a medição das temperaturas máximas e mínimas e do solo.

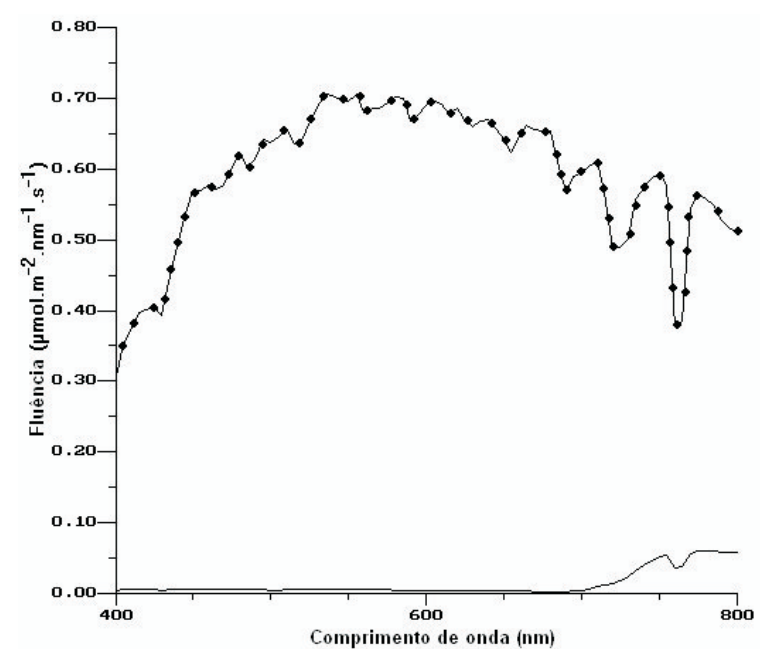

Figura 1 - Espectros da radiação solar direta (-•-) e da luz filtrada pela vegetação (-).

Figure 1 -Spectra of direct sun light (-๑) and canopy filtered light (-).
Calcularam-se a porcentagem de germinação, a velocidade média, a freqüência relativa da germinação e o índice de sincronização, de acordo com Labouriau (1983).

Devido ao fato de os dados não apresentarem distribuição normal e nem mesmo homogeneidade das variâncias, as porcentagens, velocidades e os índices de sincronização da germinação, tanto na luz quanto no escuro, foram submetidos ao teste não-paramétrico de Kuskal-Wallis (análise de variância por ranks). O efeito da temperatura, dentro dos tratamentos de luz e escuro, foi analisado pelo teste de Nemenyi para $\alpha=5 \%$ e para a comparação entre temperaturas iguais nos diferentes tratamentos de luz, bem como para verificar a emergência nos ambientes de sol e sombra foi utilizado o teste de Mann-Whitney, para $\alpha=5 \%$ (ZAR, 1999).

\section{RESULTADOS E DISCUSSÃO}

A porcentagem de sementes germinadas de Tabebuia rosea não foi afetada pela temperatura da luz, apresentando $100 \%$ de germinação na faixa de 20 a $35^{\circ} \mathrm{C}$ e sem diferenças significativas com as temperaturas de 15 e $40^{\circ} \mathrm{C}$. No escuro, a temperatura afetou a germinação e apenas a $25^{\circ} \mathrm{C}$ apresentou $100 \%$ de germinação, contudo não existindo diferença entre essa temperatura e as de 15 , 20,30 e $35^{\circ} \mathrm{C}$ (Figura 2). Não ocorreu germinação a 10 e $45^{\circ} \mathrm{C}$, caracterizando o intervalo de máxima germinabilidade entre 15 e $40{ }^{\circ} \mathrm{C}$ na luz e de 15 a 35 ${ }^{\circ} \mathrm{C}$ no escuro. Assim, as temperaturas cardeais estão entre 10 e $15^{\circ} \mathrm{C}$ a mínima e entre 40 e $45^{\circ} \mathrm{C}$ a máxima, na luz e no escuro, respectivamente. Esses resultados confirmam que espécies tropicais apresentam tolerância notável às temperaturas altas, com limite máximo igual ou superior a $35^{\circ} \mathrm{C}$ e limite mínimo geralmente acima de $5^{\circ} \mathrm{C}$ (MORAES et al., 2002). De acordo com Pezzopane et al. (2002), o sucesso das espécies vegetais em áreas abertas ou no interior das florestas está diretamente relacionado aos contrastes microclimáticos de temperatura e radiação solar observados nesses ambientes. Desse modo, a característica de tolerância à alta temperatura e à luz, apresentada pelas sementes de $T$. rosea pode propiciar altas porcentagens de germinação de suas sementes nesses ambientes florestais.

Para as sementes de Tabebuia aurea (Manso) Benth. \& Hook. F. ex. S. Moore, o intervalo de máxima germinabilidade ocorreu entre 20 e $40^{\circ} \mathrm{C}$, com valores médios acima de $80 \%$ na ausência de luz (CABRAL et al., 2003). As sementes de Jacaranda mimosifolia

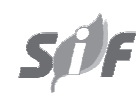

R. Árvore, Viçosa-MG, v.31, n.2, p.229-238, 2007 
(D. Don), outra Bignoniaceae, germinaram tanto na luz quanto no escuro, como as de $T$. rosea, porém em um intervalo de máxima germinabilidade menor (entre 20 e $30^{\circ} \mathrm{C}$ ) e com as temperaturas cardeais na luz e no escuro entre 15 e $20^{\circ} \mathrm{C}$ a mínima e entre 35 e 40 ${ }^{\circ} \mathrm{C}$ a máxima, respectivamente (SOCOLOWSKI e TAKAKI, 2004).

De acordo com Labouriau (1983), essas variações nas temperaturas cardeais das espécies refletem suas aptidões ecológicas e biogeográficas, possibilitando a essas espécies germinarem em uma ampla faixa de temperatura, um caráter adaptativo que propicia alta capacidade de estabelecimento em campo. Entretanto, Santos et al. (2005) verificaram que sementes de Tabebuia chrysotricha (Mart. ex DC.), com ampla distribuição geográfica, apresentaram amplitude de temperatura menor para germinação $\left(15-35^{\circ} \mathrm{C}\right) \mathrm{do}$ que Tabebuia serratifolia (Vahl) Nich e Tabebuia roseo-alba (Ridl) Sand, de distribuição mais restrita (10-35 $\left.{ }^{\circ} \mathrm{C}\right)$.

De modo geral, o comportamento germinativo das sementes de $T$. rosea foi muito semelhante na luz e no escuro em quase todas as temperaturas testadas, menos a $40^{\circ} \mathrm{C}$, em que a média de sementes germinadas na luz foi de $97 \%$ e no escuro, de $49 \%$ (Figura 2). Desse modo, conclui-se que as sementes dessa espécie não apresentam dormência. De acordo com Baskin e Baskin (1988), sementes de muitas espécies não dormentes germinam bem tanto na luz quanto no escuro e são consideradas fotoblásticas neutras, porém essa categoria não pode ser considerada como definitiva, uma vez que as sementes podem alterar suas características fotoblásticas sob determinadas condições ambientais (TAKAKI, 2001; MORAES et al., 2002).

A inibição da germinação em altas temperaturas também foi observada em sementes de Lactuca sativa L. cv Grand Rapids em temperaturas superiores a $30^{\circ} \mathrm{C}$, entretanto, quando expostas à luz vermelha, elas germinaram até $34^{\circ} \mathrm{C}$ (SAINI et al., 1989). No escuro, temperaturas altas podem causar decréscimo na quantidade de Fve, a forma ativa do fitocromo, pre-existente nas sementes, por meio da reversão no escuro (CASAL e SÁNCHEZ, 1998). Isso explicaria a maior germinação na luz com relação ao escuro (Figura 2).

R. Árvore, Viçosa-MG, v.31, n.2, p.229-238, 2007

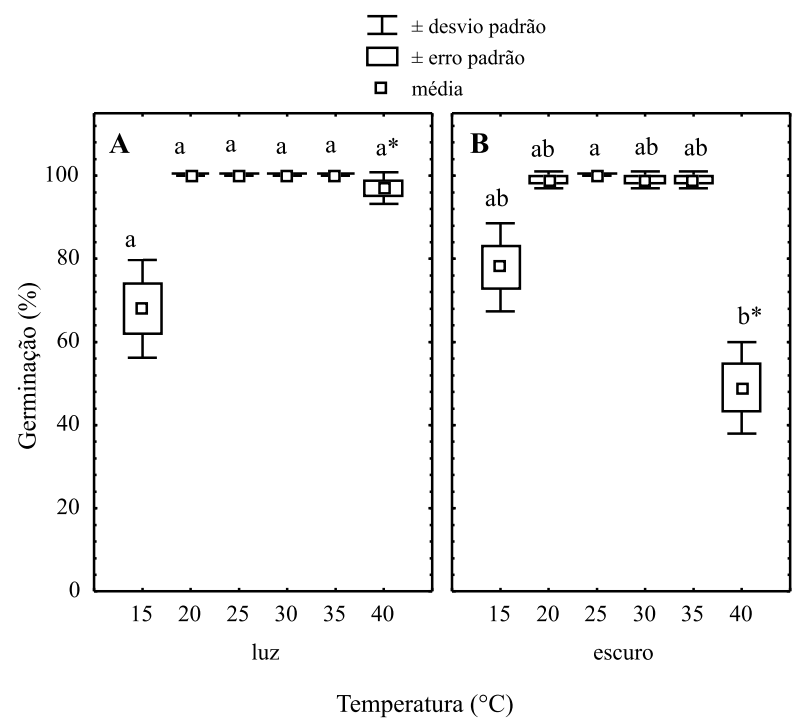

Figura 2 - Porcentagem de germinação de sementes de Tabebuia rosea incubadas na luz (A) e no escuro (B), em diferentes temperaturas. Médias com a mesma letra, dentro de cada tratamento de luz, não diferem estatisticamente pelo teste de Nemenyi $(\alpha=5 \%)$. Média com diferença significativa pelo teste de Mann-Whitney $(\alpha=5 \%)$, entre os tratamentos de luz e escuro, na temperatura de $40^{\circ} \mathrm{C}$.

Figure 2 - Germination percentage of Tabebuia rosea seeds incubated at different temperatures under light (A) and dark (B). Means followed by same letter, under the same light conditions, are not significantly different by the Nemenyi test $(\alpha=5 \%)$. Statistically different means by Mann-Whitney test $(\alpha=5 \%)$ between light and dark treatments at $40^{\circ} \mathrm{C}$.

De acordo com Labouriau (1983), na maioria dos casos a velocidade de germinação aumenta com a temperatura dentro de certo intervalo, passando a diminuir em outro, mas entre os intervalos ocorre a faixa ótima ou, em alguns casos, a temperatura ótima. O maior valor médio de velocidade de germinação foi observado a $35^{\circ} \mathrm{C}$ na luz, embora estatisticamente semelhante com os valores obtidos nas temperaturas de 20, 25, 30 e $40^{\circ} \mathrm{C}$, caracterizando a faixa de temperatura ótima de 20 a $35^{\circ} \mathrm{C}$, em que altas porcentagens foram obtidas com maior velocidade (Figura 3 ). No escuro, a maior velocidade de germinação ocorreu a $30^{\circ} \mathrm{C}$, contudo essa não diferiu das velocidades encontradas nas temperaturas de 25,35 e $40^{\circ} \mathrm{C}$, assinalando a faixa de temperatura ótima de $20 \mathrm{a} 35^{\circ} \mathrm{C}$, em que altas porcentagens foram obtidas com maior velocidade (Figura 3 ). Além disso, as sementes incubadas na luz apresentaram os 
valores de velocidade de germinação maiores que aquelas incubadas no escuro (Figura 3). Em outras espécies de Bignoniaceae, foi encontrada em sementes de $J$. mimosifolia a maior velocidade de germinação a 25 ${ }^{\circ} \mathrm{C}$, tanto na luz quanto no escuro (SOCOLOWSKI e TAKAKI, 2004), enquanto em T. aurea foi a $35^{\circ} \mathrm{C}$ (CABRAL et al., 2003) e em T. serratifolia, $T$. chrysotricha e T. roseo-alba, de 20 a $30{ }^{\circ} \mathrm{C}$ (SANTOS et al., 2005).

Os polígonos de freqüência relativa da germinação de $T$. rosea apresentaram maior homogeneidade e tendência a uma distribuição unimodal nas temperaturas de 20 a $35^{\circ} \mathrm{C}$, na luz e no escuro. Essa homogeneidade da germinação ocorre na faixa de temperatura ótima. Entretanto, a heterogeneidade e a tendência a uma distribuição polimodal dos polígonos das freqüências relativas ocorrem em temperaturas sub e supraótimas e são determinadas pela baixa velocidade de germinação das sementes, a exemplo do que ocorre a 15 e a $40^{\circ} \mathrm{C}$, tanto na luz quanto no escuro (Figura 4). Esse atraso na germinação observado a 15 ${ }^{\circ} \mathrm{C}$ também foi relatado para Myracrodruon urundeuva Allemão por Silva et al. (2002). Tais resultados concordam com Labouriau e Agudo (1987), que consideram que, em temperaturas de estresse, a heterogeneidade fisiológica das sementes é revelada.

De acordo com Labouriau e Agudo (1987), a melhor temperatura pode não ser a mesma para os parâmetros avaliados, como a germinabilidade, a velocidade e o índice de sincronização da germinação. No entanto, as temperaturas cardeais e os dados de porcentagem, velocidade e índice de sincronização da germinação podem fornecer informações sobre a agressividade da espécie na ocupação de diferentes ambientes. Em T. rosea, verificou-se que a maior sincronização da germinação ocorreu nas temperaturas de 20, 25, 30, e $35^{\circ} \mathrm{C}$ na luz. Entretanto, no escuro a maior sincronização da germinação ocorreu a $30^{\circ} \mathrm{C}$, diferindo somente de $15^{\circ} \mathrm{C}$. Além disso, observou-se que a germinação ocorreu de maneira mais sincronizada na luz, em comparação com o escuro (Tabela 1 ).

Para verificar os possíveis ambientes que T. rosea pode ocupar, foram analisadas as emergências das plântulas sob dois ambientes distintos durante 45 dias. As plântulas de $T$. rosea apresentaram maior emergência a pleno sol $(86,75 \%)$ do que sob dossel $(55,5 \%)$, com velocidades de emergência de 0,048. dia $^{-1}$ e de 0,034 . $\mathrm{dia}^{-1}$, respectivamente. Entretanto, os índices de sincronização da emergência das plântulas semelhantes, sendo a pleno sol de 2,841 "bits" e na sombra de 2,879 "bits". A velocidade de emergência menor sob o dossel ocorreu em função do atraso do início da emergência das plântulas (Figura 5). Uma possível explicação para essas diferenças poderia ser devida ao fato de a temperatura média do solo de 14,5 e a amplitude térmica de $10,9^{\circ} \mathrm{C}$, sob dossel, serem menores do que quando comparadas com a temperatura média de $21,3{ }^{\circ} \mathrm{C}$ e a amplitude térmica de $17,2^{\circ} \mathrm{C}$ a pleno sol. Apesar da menor taxa de emergência sob dossel, as taxas de sobrevivência das plântulas de $T$. rosea foram semelhantes, sendo a pleno sol de $95,5 \%$ e sob dossel de $81,6 \%$, demonstrando que suas plântulas apresentam elevada taxa de sobrevivência nesses ambientes, o que caracteriza sua habilidade de colonizar ambientes ensolarados e sombreados, corroborando os dados de germinação de sementes obtidos em laboratório.

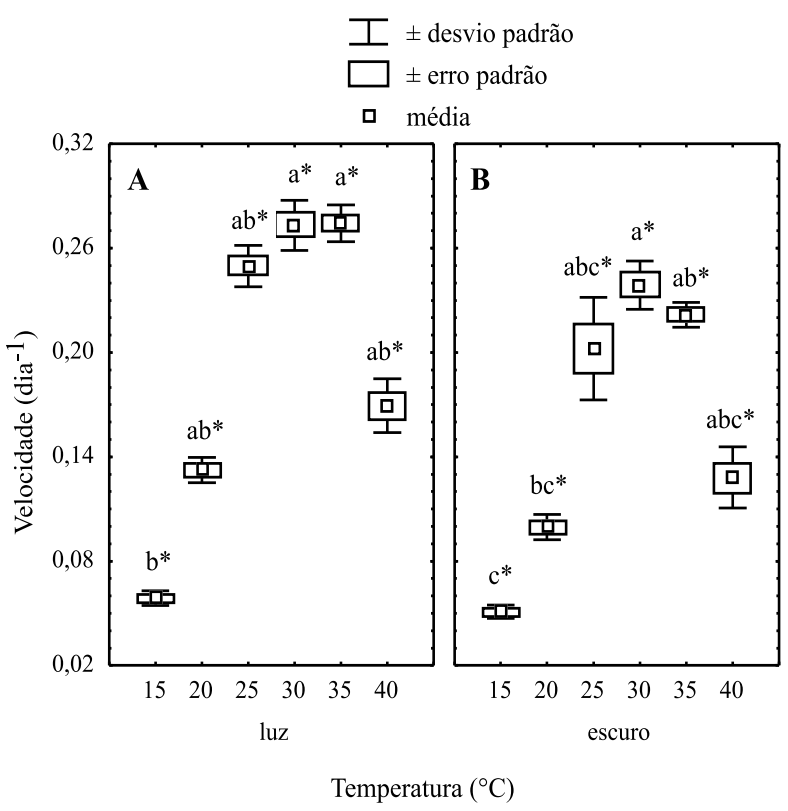

Figura 3 - Velocidade de germinação das sementes de Tabebuia rosea na luz (A) e no escuro (B), em diferentes temperaturas. Médias com mesma letra, dentro de cada tratamento de luz, não diferem estatisticamente pelo teste de Nemenyi $(\alpha=5 \%)$. * Média com diferença significativa pelo teste de Mann-Whitney $(\alpha=5 \%)$, entre os tratamentos de luz e escuro, na mesma temperatura.

Figure 3-Germination rate of Tabebuia rosea seeds incubated at different temperatures under light $(A)$ and dark $(B)$. Means with the same latter, under the same light conditions, are not significantly different by the Nemenyi test $(\alpha=5 \%)$. * Statistically different means by Mann-Whitney test $(\alpha=5 \%)$, between light and dark treatments at the same temperature.

R. Árvore, Viçosa-MG, v.31, n.2, p.229-238, 2007 

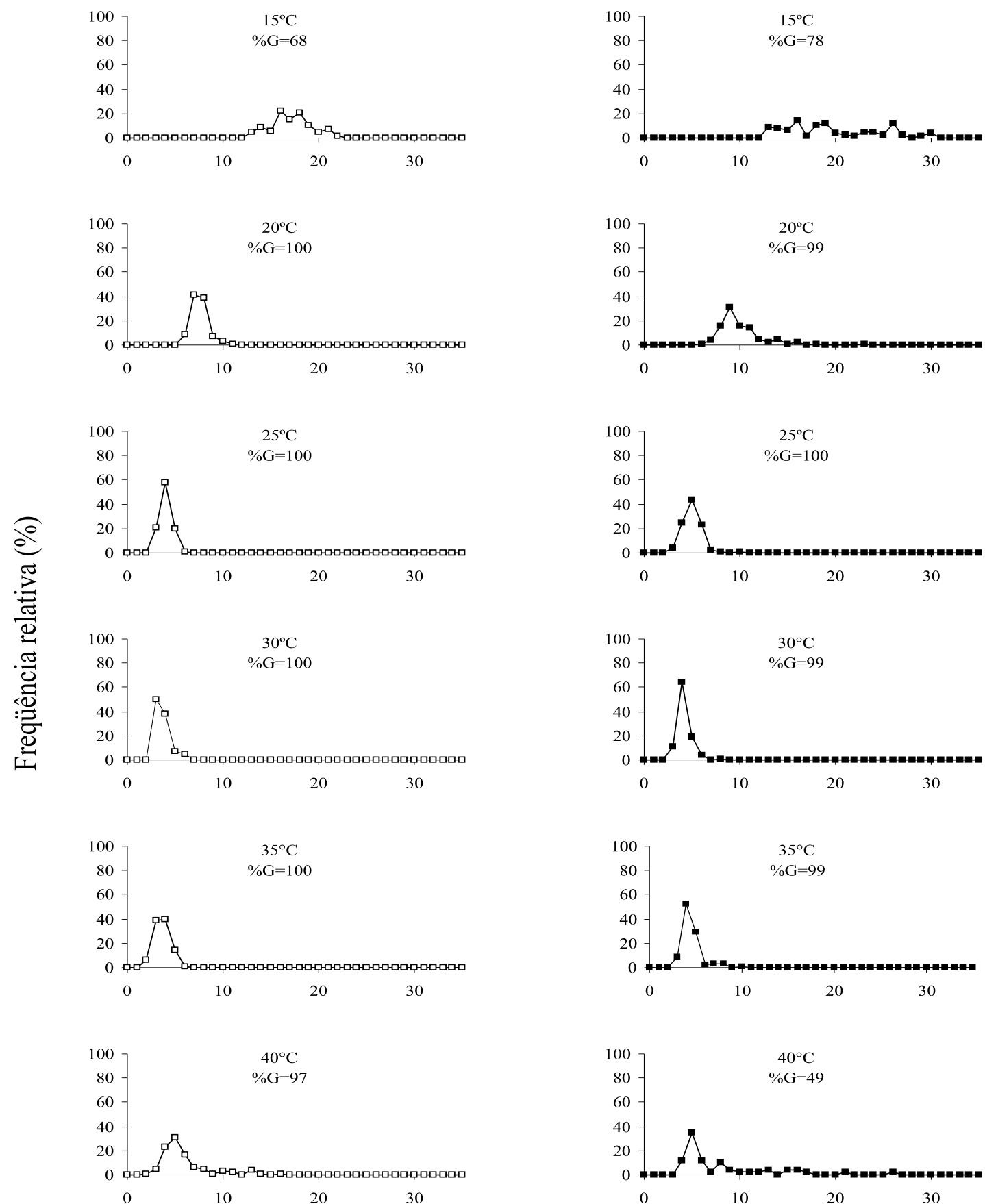

Período de incubação (dias)

Figura 4 - Polígonos de freqüência relativa da germinação de sementes de Tabebuia rosea na luz ( $\square$ ) e no escuro ( $\square$ ), em diferentes temperaturas. $\% \mathrm{G}=$ porcentagem de germinação.

Figure 4 - Polygons of relative frequency of germination of Tabebuia rosea seeds at light $(\square)$ and dark ( $\square)$ at different temperatures. $\% G=$ percentage germination.

R. Árvore, Viçosa-MG, v.31, n.2, p.229-238, 2007 
Tabela 1 - Índice de sincronização da germinação (U) de Tabebuia rosea nos tratamentos de luz e temperaturas testados

Table 1 - Synchronization Index (U) of seed germination in Tabebuia rosea under white light and dark regimes

\begin{tabular}{cll}
\hline Temperatura $\left({ }^{\circ} \mathrm{C}\right)$ & \multicolumn{2}{c}{$\mathrm{U}$ (bits) $)^{1}$} \\
\cline { 2 - 3 } & \multicolumn{1}{c}{ Luz } & Escuro \\
\hline 15 & $2,536 \mathrm{~b}^{*}$ & $3,228 \mathrm{~b}^{*}$ \\
20 & $1,643 \mathrm{ab} *$ & $2,551 \mathrm{ab}^{*}$ \\
25 & $1,352 \mathrm{a}$ & $1,543 \mathrm{ab}$ \\
30 & $1,430 \mathrm{ab}$ & $1,363 \mathrm{a}$ \\
35 & $1,622 \mathrm{ab}$ & $1,648 \mathrm{ab}$ \\
40 & $2,516 \mathrm{~b}^{*}$ & $2,383 \mathrm{ab}^{*}$ \\
\hline
\end{tabular}

${ }^{1}$ Médias seguidas de mesma letra, dentro de cada tratamento de luz, não diferem estatisticamente pelo teste de Nemenyi $(\alpha=5 \%)$. * Médias nas mesmas temperaturas, com diferenças significativas pelo teste de Mann-Whitney $(\alpha=5 \%)$, entre os tratamentos de luz e escuro.
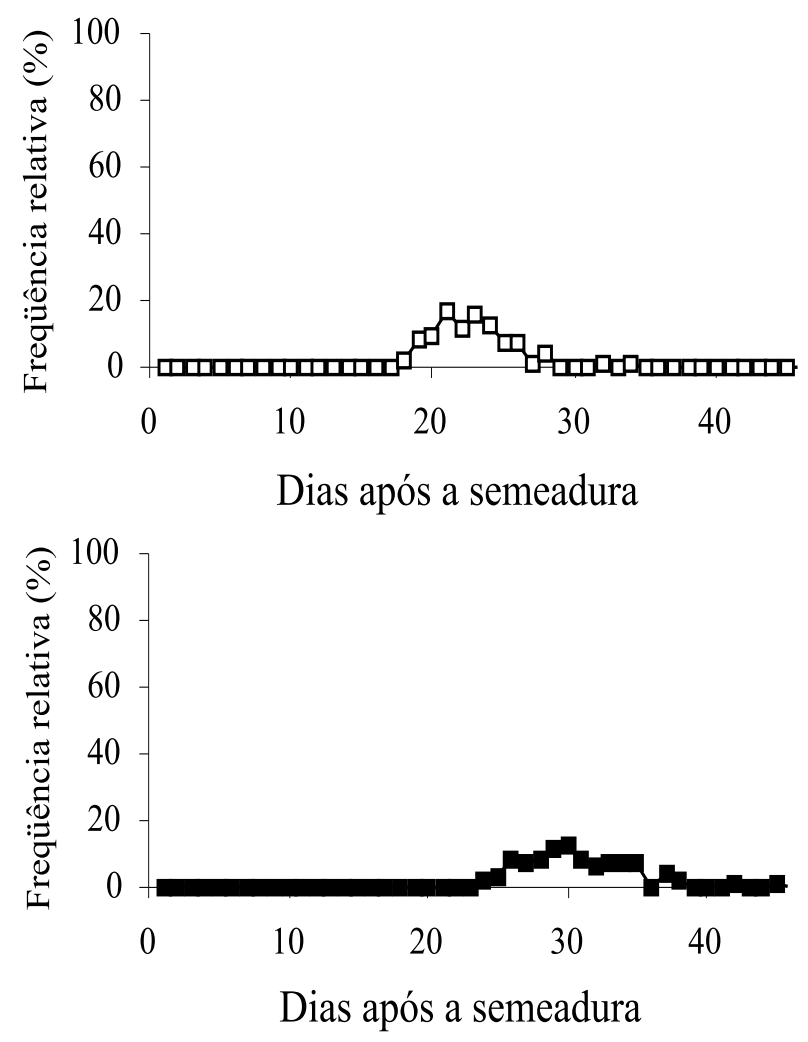

Figura 5 - Polígonos de freqüência relativa de emergência das plântulas de Tabebuia rosea no ambiente de pleno sol ( $\square$ ) e na sombra da vegetação ( $\square$ ).

Figure 5 - Polygons of relative frequency of emergence of Tabebuia rosea seedlings at the direct sun light $(\square)$ and beneath canopy ( $\square$ ).
A taxa de sobrevivência de $T$. rosea na sombra foi maior que a apresentada por Tecoma stans L. Juss. ex Kunth (1,5\%), outra espécie exótica de Bignoniaceae, apesar dos altos valores de emergência no sol e na sombra (SOCOLOWSKI e TAKAKI, dados não publicados), indicando que esta última ocupa ambientes abertos, enquanto $T$. rosea pode ocupar tanto ambientes abertos quanto áreas sombreadas pela vegetação. Entretanto, plântulas de Jacaranda copaia (Aubl.) D. Don, outra Bignoniaceae, necessitam de luz solar direta para um desenvolvimento pleno (CAMPOS e UCHIDA, 2002). Assim, o recrutamento e sobrevivência de plântulas são processos complexos que dependem de muitos fatores, como a luz solar, a temperatura, a disponibilidade de água e o tipo de solo, como também das relações de competição intra e interespecíficas e predação de plântulas.

Os resultados deste estudo indicam claramente que $T$. rosea é uma espécie potencialmente invasora, pois suas sementes germinam em uma ampla faixa de temperatura, de forma rápida, uniforme e com altas porcentagens, na presença ou ausência de luz. Isso demonstra que suas sementes, desde que com disponibilidade hídrica, podem germinar e recrutar suas plântulas tanto em ambientes abertos como clareiras, bordas de mata e pastagens (locais esses com luminosidade e temperatura altas) quanto também em locais com ausência de luz, enterradas no solo ou mesmo sob dossel no interior das florestas, onde as temperaturas são mais amenas. Soma-se a isso o fato de que as espécies exóticas geralmente se encontram livres de predadores e parasitas de seus locais de origem, o que atribui a elas vantagens competitivas sobre as espécies nativas (ZILLER, 2001).

Além do conhecimento da germinação e do recrutamento das plântulas, seriam necessários estudos sobre o desenvolvimento da espécie, já que, segundo Baruch e Goldstein (1999), Ziller (2001) e Hager (2004), muitas espécies invasoras possuem características morfológicas e fisiológicas de plantas de início de sucessão que conferem altas taxas de crescimento relativo e utilização dos recursos.

Segundo Ziller (2001), os ecossistemas mais perturbados são suscetíveis à dispersão e estabelecimento de espécies exóticas. De acordo com Rejmánek (1996) e Fine (2002), a invasão biológica pode ocorrer por um processo natural, porém a atual taxa de invasão é claramente devida à ação antrópica e tida

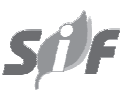

R. Árvore, Viçosa-MG, v.31, n.2, p.229-238, 2007 
como um dos mais importantes efeitos causados pelo homem sobre os ecossistemas terrestres. Em muitas regiões biogeográficas, algumas espécies invasoras têm causado problemas difíceis ou incontroláveis, necessitando, muitas vezes, de uma vigília permanente (GODEFROID et al., 2005). No caso de T. rosea, esse fato se torna ainda mais grave quando há confusão provocada pelo nome vulgar "ipê-rosa", confundindoa com $T$. avellanedae Lor. ex Griseb., T. impetiginosa (Mart.) Standl. e T. heptaphylla (Vell.) Tol., espécies da flora brasileira.

Com base nesses resultados e nas informações aqui apresentadas, fica evidente a necessidade de maior controle na distribuição e venda de mudas de T. rosea, com a finalidade de evitar os problemas de uma possível invasão da flora brasileira por essa espécie, e estudos sobre a ocorrência espontânea da espécie em ambientes naturais são urgentes.

\section{REFERÊNCIAS}

AMARAL - BAROLI, A.; TAKAKI, M. Phytochrome controls achene germination in Bidens pilosa L. (Asteraceae) by very low fluence response. Brazilian Archives of Biology and Technology, v.44, n.2, p.121-124, 2001.

ANDRADE, A.C.S. Efeitos da luz e da temperatura na germinação de Leandra breviflora Cong., Tibouchina benthamiana Cong., Tibouchina grandifolia Cong. e Tibouchina moricandia (DC) Baill. (Melatomataceae). Revista Brasileira de Sementes, v.17, p.29-35, 1995.

BARUCH, Z.; GOLDSTEIN, G. Leaf construction cost, nutrient concentration, and net $\mathrm{CO}_{2}$ assimilation of native and invasive species in Hawaii. Oecologia, v.121, p.183-192, 1999.

BASKIN, C.C.; BASKIN J.M. Germination ecophysiology of herbaceous plant species in a temperate region. American Journal of Botany, v.75, n.2, p.286-305, 1988.

BASKIN, C.C.; BASKIN J.M. Seeds:

Ecology, biogeography, and evolution of dormancy and germination. San Diego: Academic Press, 1998. 666p.

BENECH-ARNOLD, R.L.; SÁNCHEZ R.A.. Modeling weed seed germination. In: KIGEL, J.; GALILI, G. (Ed.) Seed development and germination. New York: Dekker, 1995. p.545-566.

R. Árvore, Viçosa-MG, v.31, n.2, p.229-238, 2007
BROWN, N. A gradient of seedling growth from the center of a tropical rain forest canopy gap. Forest Ecology and Management, v. 82, p.239-244, 1996.

CABRAL, E.L.; BARBOSA, D.C.A.; SIMABUKURO, E.A. Armazenamento e germinação de sementes de Tabebuia aurea (Manso) Benth. \& Hook. F. ex. S. Moore. Acta Botânica Brasílica, v.17, n.4, p.609-617, 2003.

CAMPOS, M.A.A.; UCHIDA, T. Influência do sombreamento no crescimento de mudas de três espécies amazônicas. Pesquisa Agropecuária Brasileira, v.37, n.3, p.281-288, 2002.

CASAL, J.J.; SÁNCHEZ, R. Phytochromes and seed germination. Seed Science Research, v.8, p.317-329, 1998.

FEDERER, C.A.; TANNER, C.B. Spectral distribution of light in the forest. Ecology, v.47, n.4, p.555-560, 1966.

FENNER, M. Ecology of seed banks. In: KIGEL, J.; GALILI, G. (Ed.) Seed development and germination. New York: Dekker, 1995. p.507-528.

FINE, P.V.A. The invisibility of tropical forests by exotic plants. Journal of Tropical Ecology, v.18, n.5, p.687-705, 2002.

GENTRY, A.H. Bignoniaceae. Flora Neotropica, Mongraph, v.25, n.2, p.1-136, 1992.

GODEFROID, S. et al. Ecological factors controlling the abundance of non-native invasive black cherry (Prunus serotina) in deciduous forest understory in Belgium. Forest Ecology and Management, v.210, p.91-105, 2005.

HAGER, H.A. Competitive effect versus competitive response of invasive and native wetland plant species. Oecologia, v.139, p.140-149, 2004.

LABOURIAU, L.G. A germinação das sementes. Washington: Secretaria-Geral da OEA, 1983. 174p. 
LABOURIAU, L.G.; AGUDO, M. On the physiology of seed germination in Salvia hispanica L. I. Temperature effects. Anais da Academia Brasileira de Ciências, v.59, n.1, p.37-56, 1987.

LORENZI, H. et al. Árvores exóticas no Brasil: madeireiras, ornamentais e aromáticas. Nova Odessa: Plantarum, 2003. 368p.

LÜTTGE, U. Physiological ecology of tropical plants. Berlin: Springer-Verlag, 1997. 384p.

MORAES, C.R.A.; MODOLO, V.A.; CASTRO, P.R.C. Fisiologia da germinação e dominância apical. In: CASTRO, P.R.C.; DE SENA, J.O.A.; KLUGE, R.A. (Ed.) Introdução à fisiologia do desenvolvimento vegetal. Maringá: Eduem, 2002. p.159-178.

PEZZOPANE, J.E.M. et al. Temperatura do solo no interior de um fragmento de floreta secundária semidecidual. Revista Brasileira de Agrometeorologia, v.10, n.1, p.1-8, 2002.

RANAL, M.; SANTANA, D.G. How and why to measure the germiation process? Revista Brasileira de Botânica, v.29, n.1, p.1-11, 2006.

REJMÁNEK, M. A theory of seed plant invasiveness: the First Sketch. Biological Conservation, v.78, p.171-181, 1996.

SAINI, H.S. et al. Control Processes in the induction and relief of thermoinhibition of lettuce seed germination. Plant Physiology, v.90, p.311-315, 1989 .

SANTOS, D. L.; SUGAHARA, V.Y.; TAKAKI, M. Efeitos da luz e da temperatura na germinação de sementes de Tabebuia serratifolia (Vahl) Nich, Tabebuia chrysotricha (Mart. Ex. DC.) Standl. E Tabebuia roseo-alba (Ridl.) Sand - Bignonicaceae. Ciência Florestal, v.15, n.1, p.87-92, 2005.
SILVA, L.M.M.; RODRIGUES, T.J.D.; AGUIAR, I.B. Efeito da luz e da temperatura na germinação de sementes de aroeira (Myracrodruon urundeuva Allemão). Revista Árvore, v.26, n.6,p.691-697, 2002.

SOCOLOWSKI, F.; TAKAKI, M. Germination of Jacarada mimosifolia (D. Don-Bignoniaceae) seeds: effects of light, temperature and water stress. Brazilian Archives of Biology and Technology, v.47, n.5, p.785-792, 2004.

TAKAKI, M. New proposal of classification of seed based on forms of phytochrome instead of photoblastism. Revista Brasileira de Fisiologia Vegetal, v.13, n.1, p.103-107, 2001.

VÁLIO, I.F.M.; SCARPA, F.M. Germination of seeds of tropical species under controlled and natural conditions. Revista Brasileira de Botânica, v.24, n.1, p.79-84, 2001.

VÁZQUEZ-YANES, C. et al. Light beneath the litter in a tropical forest: effect on seed germination. Ecology, v.71, n.5, p.1952-1958, 1990.

VIT, P. Tabebuia rosea (BERTOL.) DC. Ficha botânica de interés apícola em Venezuela, $\mathrm{n}^{\circ} 7$ apamate. Revista de la Facultad de Farmacia, v.46, n.1, p.57-59, 2004.

WEBSTER, C.R.; NELSON, K.; WANGEN, S.R. Stand dynamics of an insular population of an invasive tree, Acer platanoides. Forest Ecology and Management, v.208, p.85-99, 2005.

ZAR, J.H. Biostatiscal analysis. 4. ed. New Jersey: Prentice Hall, 1999. 929p.

ZILLER, S.R. Plantas exóticas invasoras: a ameaça da contaminação biológica. Ciência Hoje, v.30, p.77-79, 2001. 